\title{
Effect of value-added services on transactional behaviour
}

\author{
Zoleka Mthembu \\ Seugnet Bronkhorst \\ University of Johannesburg, South Africa
}

\section{Keywords}

Value Added Services, redemptions, utilisation, qualifying, customer base, South African banking industry

\begin{abstract}
Traditional banking methods evolved and included services as a method of differentiation, reducing operating costs, and providing additional benefits to the customer. Banks re-invented themselves and provide innovative solutions to remain competitive. This research explores whether using value added services contributed to changes in transactional banking behaviour and was done in one of the largest banks in South Africa over a period of four months. Two banking products in the youth customer segment were selected. The control group received one treatment at the beginning of the four-month period, and the experimental group received a further three treatments at different times of each month. Two data sets (1) VAS usage and (2) bank transactions were analysed. The results showed that the intervention had a positive effect on transactional banking behaviour. Additional causative factors were identified that increased the usage of value-added services and increased transactional banking behaviour.
\end{abstract}

Corresponding author: Seugnet Bronkhorst

Email addresses for the corresponding author: sbronkhorst@uj.ac.za

The first submission received: $10^{\text {th }}$ December 2020

Revised submission received: $14^{\text {th }}$ March 2021

Accepted: $5^{\text {th }}$ April 2021

\section{The Introduction}

The research focused on Value Added Services, as a marketing tool used by banks with the objective of increasing banking products' usage by the targeted customer. Highlighting the collective names given to similar programmes such as loyalty and reward programmes, companies aimed to meet the consumers' needs and objectives and the company or brand's objectives, to increase usage of products and increase sales and profits. A distinction between two types of VAS where it was a prerequisite that a customer performed a specific behaviour, such as performing a transaction before qualifying to receive an incentive, and where an incentive is made available to the customer with no conditions or prerequisite behaviour attached, was drawn. Three aims of VAS programmes, being, programmes that disbursed rewards to customers merely for establishing a relationship with the bank (for example, opening a bank account), programmes that awarded points to customers, rewarding their transactional behaviour, and lastly product-specific rewards, were highlighted. These incentive-based programmes needed to become tailored to target specific customer segments and provide a variety of choices to customers, including personalised services and communication to customers (Perkins, 2018:74). It is against this backdrop that the research focused on VAS as it relates to the transactional behaviour of a specific customer segment, the youth customer. Through research literature on incentive-based programmes and young customers, and quantitative data analysis of the research experiment case study, the study aimed to determine whether VAS had an impact on transactional banking.

\section{Literature Review}

Rewarding or enticing the customers using something that appeals to them, is a widely used strategy to drive usage and encourage brand loyalty that has been practised among a number of disciplines and industries (Nevskaya \& Albuquerque, 2019:380). Different names have been used to describe these programmes and all have different objectives. The most common names that are used are loyalty and reward programmes. Chaudhuri et al. (2019:640) describe it as a "marketing investment designed to foster behavioural loyalty, and enhance services, in the form of non-core services". These 
programmes are also referred to as "servitisation" which is the "bundling of products with related services" (Zhang et al., 2015:26).

\subsection{Bank $Z$ as a VAS provider case study experiment}

Bank $Z$, one of the largest banks in South Africa providing financial products and services, was used for the research study. The study focused on Bank Z's product $Y$ and Students, a bank account targeting customers under the age of 18, and students registered at an institution of higher learning, respectively. The rationale for choosing the youth customer was driven by data analytics from Bank Z's data warehouse extracted by De Jager (2015), which showed that the average income of a customer joining the bank before the age of 20 brings in three times the average income of a customer that joins the bank after the age of 20. Furthermore, price sensitivity was a motivation for choosing these specific products as the banks did not charge monthly fees for these products. The VAS offered by Bank Z included discount vouchers at popular retailers and given that these are not banking products, they were provided by a third party.

\subsection{Summary of the literature}

Literature shows limited sources and research on VAS specifically, and a significant number of sources and studies were only conducted on other incentive-based programmes. Given the similarities between VAS and these programmes, the recommendations in the literature reviewed were practically applied to VAS. The studies highlighted the characteristics of successful programmes which included a simple construct that is easily understood by the customer, a personalisation, low running costs, a high usage, high customer value, acquisition, and retention (Nastassoiu \& Vandenbosch, 2019:208; Perkins, 2018:75). In measuring programme success, Chaudhuri et al. (2019:640) showed a correlation between the introduction of a loyalty programmes and an increase in sales and gross profits (albeit as a short-term benefit) within the first year of such an intervention.

The most relevant to this particular study was repeated usage of the product, measured by customers' increased motivation to pay for a product, repetitive purchasing behaviour, increased usage and consumption, and willingness to refer other customers to use the products (Watson et al., 2015:791). The study also discussed literature recommendations for promoting usage. For instance, a recommendation by Bazargan et al. (2017:353) and Nevskaya and Albuquerque (2019:379) included explicit instructions on how to reach the next level, creating scarcity by setting an expiry date to the redemption of the incentive (for example, vouchers) as a measure to avoid devaluating the value of the rewards. These methods seem to be particularly useful to the young customer (Buszko et al., 2019:156; Wijland et al., 2016:56). Another recommendation made included scarcity messaging such as "available for a limited time only" or "on sale now, subject to availability" to promote purchases. Literature also encourages the aspect of allowing customers flexibility when it comes to methods of redemption (for example cash points) and variety of vouchers being offered to customers as a way of encouraging usage (Dorotic et al., 2014:340).

Creating value for both the customer and the firm, should be a key objective of banks (Nevskaya \& Albuquerque, 2019:398). The research discussed studies on customer perceptions of VAS in the banking sector, where findings recommended that banks should provide a network of services that are technologically advanced, accessible on mobile phones, and are targeting a specific customer segment as a way of enhancing the bank's offering (Mahalakshmi \& Saravanaraj, 2013:2845). The research further highlighted the importance of understanding the customer when developing products and services that would attract the customer and promote repeated use of the products and services (Roberts-Lombard \& Paramasur, 2015:2). The need for banks to focus on what is relevant to the youth customer at this stage of their lives, the necessity of designing solutions that meet those needs and communicating these solutions in simple, easily understood language was also emphasised in the research. In highlighting the need to understand the youth customer, the study focused on the youth banking aspects that were of relevance to the customer including the use of mobile phones, technology, and digitalisation (Salem et al., 2019:426). This customer segment is cited as having a proclivity for using banking mobile apps with a preference for functionalities like the ability to open multiple accounts, transfer between accounts, add personalised 
images, and at the same providing convenience (Wijland et al., 2016:56). Furthermore, the use of the branch was unflavoured and inconvenient (Chan et al., 2017:282).

Another key aspect further discussed was the customers' social environment, specifically highlighting the fact that the people closest to them influenced usage decisions (Hefner et al., 2019:82). The literature postulated the differences in age of young people and the contrasting influence that the young customer has on convincing a parent to make a purchase, and how organisations can use this to their advantage. This implicated a rebellious influence among teenagers and children, pestering the parent until a purchase was made (Chan et al., 2017).

The importance of engagement between the youth customer and the brand utilising the advancement in technology and use of smartphones and social media which facilitate easy and regular engagement, was indicated by Kumar and Reinartz (2016:36). In engaging the customer, the bank ensures that a continuous flow of information takes place between the customer and the brand. A challenge would be communicating financial information in an emotive and relational manner (Al-Rabayah et al., 2017:60).

\section{Research methodology}

The study used the quantitative research methods, data mining collection techniques and descriptive statistics. The observation data collection method was used in the research where the control group (with subjects receiving only one SMS advising them about the VAS), and the experimental group (with subjects receiving repeated SMSs advising them about the VAS at the beginning of the month, in the middle of the month and at the end of the month) were observed between November 2018 and February 2019. Data was collected from two secondary data sets, from the bank's enterprise data and the redemption data from the vouchering system using SQL. For the research experiment, the relevant transactional behaviours that were included were deposits, transfers, purchases and prepaid purchases. The research was done using positivist and post-positivist paradigms associated with the quantitative research method, with the latter responding to the shortcomings of the positivist approach (Yin, 2018:62).

The population sample of the research consisted of Bank Z's youth banking in the Gauteng Province, selected on the basis that the researcher resided and was employed in the province. Additionally, the accounts were selected from those customers who provided marketing consent upon opening the accounts, thereby eliminating a burden of requesting customer consent for the experimental and control group for the research. For the experiment group, the research targeted a sample total of 1500 $\mathrm{Y}$ accounts and a total of 4000 Students accounts, with 1083 from the $Y$ account and 3533 from the Students accounts (a total of $83.92 \%$ of the sample size) making up the experimental group and matching the control group.

The research also detailed the treatment given to the control group and the experimental group, wherein the control group was only exposed to a welcome SMS advising the customer of the VAS in the beginning of month 1, with no other treatment or communication made afterwards; and the experimental group being exposed to three treatments, at the beginning of the month, the middle and the end of the month. Data was collected at the beginning and the end of the four-month period (pre-test and post-test) to allow for the full implementation of the interventions.

\section{Findings}

The aim of the research was to determine the effectiveness of using VAS on the youth customer's transactional behaviour by analysing the usage of these services as its primary objective. The study further sought to achieve the secondary objectives of:

- determining whether there is a difference in transactional behaviour between VAS users and nonVAS users.

- determining whether the customers' knowledge of the VAS has an effect on customers' transactional behaviour; and

- determining whether there are any demographic factors that influence the usage of VAS, and the research question.

\subsection{Analysis of research results}

Only youth customers in the Gauteng Province were targeted as a population, the total targeted sample consisted of 11000 customers, with 3000 customers being Y account holders and 8000 customers 
being Student's account holders. The account holders were then divided into two groups (1:1), the experiment and the control group. Of these groups, a further 1083 out of 1500 customers were selected from the $\mathrm{Y}$ account holders, and 3533 out of 4 000, from Student's account holders, making up the experiment group. The experiment group, constituting $83.92 \%$ of the targeted sample was exposed to the intervention, and the control group was not exposed to the intervention. The intervention received by the experimental group, included the introduction, modification and communication of VAS to customers at level 1 to 3, three times in one month over a period of four months (where level 1 included the provision of information about the type of VAS, customers' ability to choose a type of VAS, and the conditions under which customers had to perform a transaction; level 2 where customers received reminders about the VAS, and the SMSs were not blanket SMSs, but were personalised with each customer's SMS bearing the customer's name; and level 3 where each communication or SMS was personalised with each customer's name and was adapted to the customer's previous usage where there was history of usage).

The results of the quantitative research are shown in Table 1. The effect size was calculated by subtracting the mean transactions per cluster at the end of the $4^{\text {th }}$ month, from the mean of the clusters at the end of the $1^{\text {st }}$ month and further expressed as a percentage delta.

Table 1: Mean analysis of Y- Experimental group

\begin{tabular}{|c|c|c|c|c|c|c|c|c|c|c|c|c|c|c|c|c|c|c|c|c|c|c|c|}
\hline 1 & Month & \multicolumn{11}{|c|}{1} & \multicolumn{10}{|c|}{4} & \multirow[t]{2}{*}{ DELTA } \\
\hline 2 & CLUSTERS & 1 & 2 & 3 & 4 & 5 & 6 & 7 & 8 & 9 & 10 & 11 & 1 & 2 & 3 & 4 & 5 & 6 & 7 & 8 & 9 & 10 & \\
\hline 3 & \#ACCOUNT & 586 & 312 & 69 & 56 & 21 & 18 & 9 & 5 & 4 & 2 & 1 & 686 & 294 & 51 & 24 & 11 & 8 & 4 & 2 & 2 & 1 & \\
\hline 4 & System_Debit Orders In & 0 & 0 & 1 & 1 & 1 & 0 & 1 & 0 & 1 & 1 & 0 & 0 & \begin{tabular}{|l|l|}
0 \\
\end{tabular} & 0 & 1 & 0 & 1 & 1 & 0 & 3 & 0 & $521 \%$ \\
\hline 5 & Internet_Prepaid Airtime & 0 & 0 & 1 & 0 & 1 & 0 & 1 & 2 & 0 & 0 & 0 & 4 & 0 & 0 & 1 & 0 & 0 & 0 & 8 & 2 & 0 & $1359 \%$ \\
\hline 6 & Bank Merchants_Point of Sale & 2 & 3 & 0 & 1 & 2 & 1 & 8 & 2 & 4 & 3 & 1 & 2 & 0 & 0 & 7 & 4 & 6 & 8 & 6 & 3 & 0 & $3493 \%$ \\
\hline 7 & Internet_Transfers In & 1 & 0 & 2 & 1 & 2 & 1 & 3 & 1 & 4 & 1 & 1 & 2 & 0 & 1 & 2 & 1 & 4 & 2 & 2 & 3 & 3 & $1744 \%$ \\
\hline 8 & Bank Merchants_Purchase and Cash Withdrawal POS & 0 & 0 & 0 & 0 & 0 & 0 & 0 & 0 & 0 & 0 & 0 & 0 & 0 & 0 & 0 & 0 & 1 & 0 & 0 & 0 & 0 & $30 \%$ \\
\hline 9 & Bank ATM_Cash Withdrawals & 0 & 0 & 0 & 0 & 0 & 0 & 2 & 1 & 1 & 1 & 0 & 2 & 0 & 0 & 1 & 0 & 1 & 1 & 4 & 0 & 0 & $776 \%$ \\
\hline 10 & Cash Acceptor ATM_Cash Withdrawals & 0 & 0 & 0 & 0 & 1 & 0 & 1 & 0 & 0 & 0 & 0 & 2 & 0 & 0 & 1 & 0 & 1 & 1 & 0 & 0 & 0 & $429 \%$ \\
\hline 11 & Bank APP_Own Defined Payments & 0 & 0 & 0 & 0 & 0 & 0 & 0 & 1 & 0 & 0 & 0 & 0 & 0 & 0 & 0 & 0 & 0 & 0 & 0 & 0 & 0 & $-108 \%$ \\
\hline 12 & Non Bank Merchants_Point of Sale & 0 & 0 & 0 & 0 & 0 & 0 & 1 & 8 & 0 & 0 & 0 & 0 & 0 & 0 & 0 & 0 & 0 & 0 & 1 & 0 & 0 & $-652 \%$ \\
\hline 13 & Cash Acceptor ATM_ATM Cash Deposit & 1 & 0 & 0 & 0 & 0 & 0 & 0 & 0 & 0 & 0 & 0 & 4 & 2 & 0 & 0 & 0 & 0 & 0 & 0 & 0 & 0 & $616 \%$ \\
\hline 14 & Teller_Cash Deposits & 0 & 0 & 0 & 0 & 0 & 0 & 0 & 0 & 0 & 0 & 1 & 0 & 0 & 0 & 0 & 0 & 0 & 0 & 0 & 1 & 0 & $-255 \%$ \\
\hline 15 & Non Bank ATM_Cash Withdrawals & 0 & 0 & 0 & 0 & 0 & 0 & 0 & 0 & 0 & 0 & 0 & 0 & 0 & 0 & 0 & 0 & 0 & 0 & 1 & 0 & 0 & $70 \%$ \\
\hline 16 & Internet_Transfers Out & 0 & 0 & 0 & 0 & 0 & 0 & 0 & 0 & 1 & 0 & 0 & 0 & 0 & 0 & 0 & 0 & 1 & 0 & 0 & 0 & 0 & $19 \%$ \\
\hline 17 & Cash Acceptor ATM_Transfers Out & 0 & 0 & 0 & 0 & 0 & 0 & 0 & 0 & 0 & 0 & 0 & 0 & 0 & 0 & 0 & 0 & 1 & 0 & 0 & 0 & 0 & $50 \%$ \\
\hline 18 & Bank Merchants_Cash Withdrawals & 0 & 0 & 0 & 0 & 0 & 0 & 0 & 0 & 0 & 0 & 0 & 0 & 0 & 0 & 0 & 0 & 1 & 0 & 0 & 0 & 0 & $55 \%$ \\
\hline \multirow[t]{5}{*}{19} & Cash Acceptor ATM_Cash Deposits & 0 & 0 & 0 & 0 & 0 & 0 & 0 & 0 & 0 & 0 & 0 & 0 & 0 & 0 & 0 & 0 & 0 & 1 & 0 & 0 & 0 & $86 \%$ \\
\hline & Card Swipe & & & & & & & & & & & & & & & & & & & & & & \\
\hline & Money-in & & & & & & & & & & & & & & & & & & & & & & \\
\hline & Prepaid purchase/airtime/data & & & & & & & & & & & & & & & & & & & & & & \\
\hline & Money-out & & & & & & & & & & & & & & & & & & & & & & \\
\hline
\end{tabular}

Source: Bank Z internal

The research selected a multivariable analysis using an unsupervised cluster analysis as the programme allowed cluster without instruction from the researcher. The information generated by the programme showed the results for the first month (November 2018) and the final month of the research (February 2019) and showed the changes and differences brought about by the intervention to the experimental group over the four-month period. Row 2 in Table 1 comprises the number of clusters, with Row 3 indicating the number of accounts in each cluster. The sum of number of accounts adds up to 1083 account holders or customers in the $\mathrm{Y}$ account section (the experimental group).

\section{Internet prepaid airtime}

Row 5 in Table 1 shows the mean Internet prepaid airtime transactions carried out by customers over the four-month period across product $Y$ accounts. The results show that only a mean of 5 transactions were made in the month of November 2018, and there was an upsurge to 15 transactions by February 2019, an increase of up to $1359 \%$ according to the Delta results shown. By contrast, row 5 in the control group in Table 2 shows a decline in the number of transactions between the months of November 2018 and February 2019, where a 450\% decrease was recorded in four months, as shown in the delta 
column. This upsurge in the experimental group may be attributed to the modification and repeated communication about the VAS by the bank, which led to the increase in the customers' transactional behaviour in this specific category of transactions. Prepaid airtime and data purchase by customers is a prominent purchase, given the wide use of cell phones and the need to stay connected. The results show a positive correlation between customers increased transactional behaviour and the introduction, modification and communication of VAS. The results recorded over the four-month period confirm the findings by Chaudhuri et al. (2019:640) that the introduction of a VAS programme has a short-term benefit of increasing sales within the first year. In this case, the bank is a reseller of prepaid airtime and commission income received from the sales thereof.

\subsubsection{Bank Merchants Point of Sale (POS)}

Row 6 in Table 1 shows the Bank's experiment group's merchants point of sale (POS) records during the period. At the end of month 1, only 27 POS transactions were recorded, compared to a mean of 36 POS transactions recorded at the end of month 4 . The delta column provides the difference between the 2 periods calculated as a percentage change. The delta column shows that the number of POS transactions increased by $3493 \%$ in four months. In comparison, row 6 in Table 2 shows the control group's results for the same transaction. In month 1, a mean of 8 POS transactions was recorded, compared to only 2 transactions performed in month 4 , showing a marked decrease of up $200 \%$ as shown in the delta column. This increase in the experiment group can be attributed to the effects of VAS, and the interventions provided to this particular group over the four-month period. The results affirm Kumar and Reinartz's (2016:36) assertions that engagement or communication with the customer is important for the success of a marketing strategy, which in this case is the VAS. As results show, the opposite, that is, the absence of communication and modification of VAS can lead to a decrease in the number of transactions performed by customers. The increase on the POS transactions over the four months recorded in the experimental group, also confirms Al-Rabayah et al.'s (2017:162) recognition that customer engagement is a key factor in customer retention, although their study focused on the use of social media.

Furthermore, when looking at the Y customers' transactional behaviour for POS transactions, in month 1, the largest cluster of account holders, cluster 1, each account holder performed a mean average of 1 transaction, compared to month 4 , where a mean average of 2 transactions were performed per account holder. This shows a marked increase which can be attributed to the interventions.

\subsubsection{Internet transfers in (EFT)}

Row 7 on Table 1 indicates the results of the experimental group, the results for Internet transfers (EFT) into the accounts in month 1, a mean of only 17 transactions was recorded, and by the end of month 4 , the number of transactions had increased to 20, showing an increase on the delta column of up to $1744 \%$. By contrast, showing results of the control group, highlight a decrease in the number of transactions from 11 in the same period, a total decrease of $125 \%$. The increase in experiment group transactions can also potentially be attributable to the interventions. Given that this transaction is Internetbased, the results are in line with Wijland et al.'s (2016:52) observations that the youth banking customer experience is associated with mobile and Internet banking. The ease of use, speed and overall convenience of transacting using Internet banking, the increase in this type of transaction by the youthful customer also supports Chan et al.'s (2017: 282) findings. It is therefore not surprising that Internet banking transactions increased in the four-month period of the research.

\subsubsection{Non-teller deposits}

Row 13 in Table 1 of the experiment group indicate the results of ATM cash deposits over the fourmonth period. Results show that in November 2018, only one transaction was performed from the youth customers in Gauteng, and after the four-month period, 6 non-teller deposit transactions were performed, signalling an upsurge of $616 \%$ as the delta column. In comparison, the same row 13 in the control group column shows a significant decrease in the same transaction recording a higher number of 10 transactions, and in the last month, recording 4 transactions, a decrease of $150 \%$. Although, the messaging did not specify the channel to be used when making the deposits, the customer still chose to make use of an alternative physical channel to make these deposits. These results also attest to the findings of Chan et al. (2017:282), stating that a segment of youth is not inclined to go inside the branch. 


\subsubsection{Teller cash deposits}

Row 14 in Table 1 exhibits the results of the teller cash deposit transactions performed within the four-month period. Interestingly, this is the only money in transaction that did not show an increase during the research experiment. In the first month of the experiment, only 1 teller cash deposit was performed, and by the last month of the experiment, only 1 cash teller transaction was observed, marking a decrease of up to $-255 \%$ according to the delta column showing the shifts during the experiment. Row 14 in Table 11 also shows a decrease in teller deposits for the control group where 19 transactions were recorded and in the fourth month, only 4 transactions were recorded, showing a $75 \%$ decrease. The results show that other factors may be at play in influencing this particular type of transaction that may not be mitigated by the interventions. 


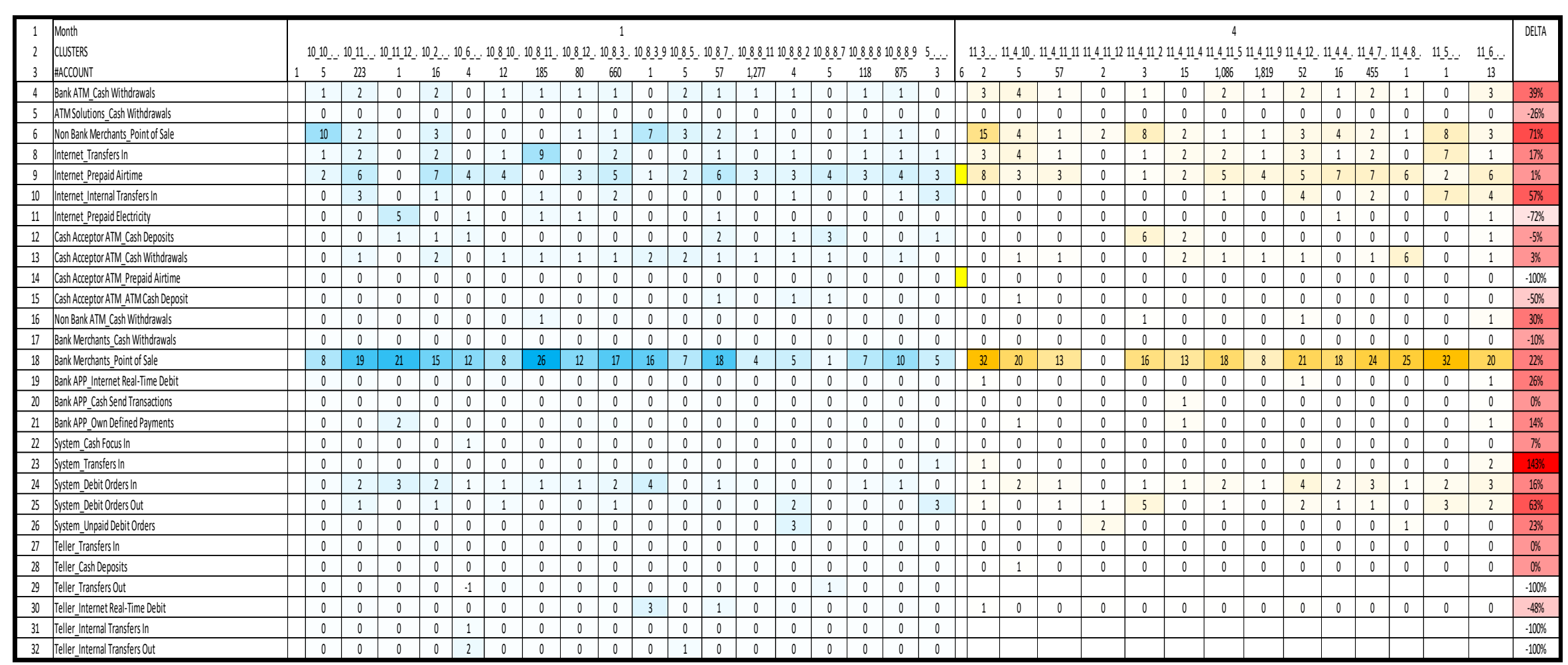

Table 2: Mean analysis: Experimental group for the Students account

Source: Bank Z internal 
Table 2 shows the results for experiment group for Student's account holders. The Students account has more features than the $\mathrm{Y}$ account, as such there is a longer list of transactions recorded. For the purposes of comparing like-for-like, the same transactions are analysed, the Internet Prepaid airtime, the Point of Sale (POS), Internet transfers and non-teller deposits and teller deposits. The POS transactions for the experiment group in Table 2, row 18 show an increase of up to $22 \%$, while row 20, between month 1 and month 4.

For the Internet prepaid airtime transactions, the experiment group shows a marked increase in the delta shift column, of $1 \%$ between month 1 and month 4 , an interestingly insignificant increase. This may be due to the timing of the year, but the intervention had showed no sign of a noticeable impact. The control group results show an increase of 100\% between the period of November 2018 and February 2019. This is a sharp contrast between the Product $Y$ results and Student results for this specific transaction. No known explanation can be given for these results.

When it comes to Internet transfers-in (EFT) transactions, the experimental group results in Table 2 show an increase over four months in the number of transactions of up to $57 \%$ as indicated in the delta shift column. This increase in the experimental group result can be attributed to the intervention or the fact that the transfer may have been done by a family member with a Bank $\mathrm{Z}$ account.

For the non-teller deposits (cash acceptor ATM cash deposits), the experimental group shows a decrease in the number of transactions, of up to $5 \%$, compared to the control group's results in Table 2 which shows a significant decrease in the number of transactions over a four-month period, by $84 \%$. Lastly, the teller deposits for the experiment group in Table 2 show no movement, compared to the 7\% increase for the control group over the same period. This non-increase in the experimental group may concur with Chan et al.'s (2017:285) findings that the youth banking customer is not fond of banking in the branch.

\subsubsection{Effectiveness of using VAS on the youth customer's transactional behaviour}

From the research results, it is evident that using the VAS for youth customers to influence their transactional behaviour is effective, more so in the younger group of customers, product $Y$. Given the age demographic of the research, including students and children, the results indicate marked changes of the youth customers' transactional behaviour due to the VAS intervention. The positive results, mostly showing increases in the youth customers' transactional behaviour across transactions such as Internet prepaid airtime, EFTs and deposits, give a good indication of the effectiveness of using VAS on the youth customers' transactional behaviour.

The decrease or rather the non-increase in the use of teller cash deposits transactions signals amongst other things, that this type of transaction may not be seen as valuable or convenient to a youthful customer (Chan et al., 2017:282). As Wijland et al, (2016:56) highlight, the youth customer is more in tune with much faster, more convenient, and effortless types of transactions.

The effectiveness of VAS on the youth customers' transactional behaviour can also be attributed to the use of products and services that appeal to youth customers, in line with Hoffman's (2019:118) assertions. The results of the research experiment also analysed the redemptions made by these customers. These results show marked inclination towards smartphone, Internet, and app banking. Table 19 further shows VAS products in the Y product that are popular with the customer that were redeemed, including connectivity (through data and airtime) food vouchers, activity, and travel vouchers. The results show that $67.35 \%$ of redemptions were made by the experiment group, highlighting that the majority of the users of VAS were those who performed more transactions. By contrast, the redemption rate for the control group, which was only exposed to one treatment in the first month, was a mere $32.65 \%$. The results also show that the connectivity (redemption of data vouchers) tops the VAS redemption vouchers redeemed by the youth customers at $57.61 \%$. This is followed by food voucher redemptions at $29.04 \%$, with activity and travel vouchers being the least redeemed vouchers, respectively. This information is crucial for modifying the VAS and giving the youth customer choices of the types of redemptions that they value the most (in this case, connectivity). 


\subsubsection{Analysis of transactional behaviour between VAS users and non-VAS users}

The research also sought to analyse whether there is any difference in the transactional behaviour of VAS users and non-VAS users. The analysis shows the results of the entire youth banking customer base and was further categorised between VAS and non-VAS users across Bank Z's product $Y$ and Students accounts, with further disaggregated data showing the experiment group. The total number of transactions for the experiment group for product $Y$ users is also shown. Furthermore, Table 2 indicates the average number of transactions per customer each month of the four months to highlight changes, if any, on transactional behaviour between non-VAS and VAS-users. Three types of categories of transactions were used to make this analysis, namely, deposits/transfers-in, POS purchases and prepaid purchases (airtime and data). Categorisation was then made between the total transactions in each type of transaction between VAS users and non-VAS users.

The numbers in the columns indicate results over a period of 4 months. For each group, the results showed an average number of transactions performed by the customer. In the non-users' category, the average transaction per customer in the month of November 2018 was 0.6 compared to the VAS users' average transaction per customer of 2.1 in the same month. For the experiment group in the first month of the intervention (November), the results showed a higher average of transactions per customer, when compared to customers who made use of the VAS, but were not part of the experiment, 3.2 as compared to 2.1. These averages are both above the 0.5 average of non-users in the entire youth banking customer base in the same period. In December 2018, the overall non-users' average transaction per customer was 0.6 compared to the overall VAS users at 2 average transactions per month. For the experiment group, a significant increase of an average of 6.7 transactions was recorded in the month of December. In January, the third month of the experiment, the overall non-VAS users' average transaction per customer was 1.1 compared to the VAS users' group of 1.8 transactions in the same month. For the experimental group, the increase recorded in the month of January was quite significant, at an average of 8 (7.9) transactions. In February, the last month of the experiment, the overall non-VAS average transactions per customer was 0.9 compared to the overall VAS user transactions per customer which was recorded at 1.8 for the same month. The VAS-users recorded yet another significant average increase to 9 (8.7) transactions.

The results show a consistent higher than average transaction per customer for VAS users as compared to non-VAS users for the same period. Although some months show an increase in the number of average transactions per customer, the results still show the average VAS users' transactions per customer to be higher than the non-VAS users' transactions for the same period. In the experiment, the experimental group has consistently shown a significant increase in the average number of transactions, showing a correlation between VAS and transactional behaviour of customers, wherein the introduction of VAS promotes an increase in customers' transactional behaviour. Table 3 summarises the results of the comparison of transactional behavior between VAS users and non-VAS users.

Table 11: $\quad$ Results of the analysis of transactional behaviour between VAS users and non-VAS users

\begin{tabular}{|c|c|c|c|c|c|c|c|c|}
\hline & & & & & \multicolumn{4}{|c|}{ Gauteng } \\
\hline & Nov' 18 & Dec '18 & Jan '19 & Feb'19 & Nov' 18 & Dec'18 & Jan '19 & Feb'19 \\
\hline Total Customers (users+non-users) & 350,546 & 349,607 & 351,459 & 352,532 & 32,642 & 32,142 & 32,966 & 44,680 \\
\hline Users only & 158,056 & 157,981 & 119,744 & 121,156 & & & & \\
\hline Deposits/Transfers-in & 192,624 & 154,654 & 98,990 & 105,259 & & & & \\
\hline POS purchases & 182,567 & 122,764 & 124,336 & 186,544 & & & & \\
\hline Prepaid purchases & 403,453 & 483,563 & 435,214 & 380,743 & & & & \\
\hline Total & 778,644 & 760,981 & 658,540 & 672,546 & & & & \\
\hline Average Transaction/customer & 2.221232021 & 2.176675524 & 1.873732071 & 1.907758728 & & & & \\
\hline Non-users & 83,002 & 85,134 & 153,926 & 124,809 & & & & \\
\hline Deposits/Transfers-in & 46,327 & 36,400 & 36,521 & 32,441 & & & & \\
\hline POS purchases & 4,451 & 4,171 & 3,796 & 2,336 & & & & \\
\hline Prepaid purchases & 37,764 & 36,752 & 51,402 & 40,879 & & & & \\
\hline Total & 88,542 & 77,323 & 91,719 & 75,656 & & & & \\
\hline Average Transaction/customer & 0.575224459 & 0.619530643 & 1.105021566 & 0.888669627 & & & & \\
\hline Users & 10,977 & 10,515 & 10,047 & 10,949 & 1,083 & 1,083 & 1,083 & 1,082 \\
\hline Deposits/Transfers-in & 8,349 & 7,986 & 7,631 & 8,415 & 998 & 1,114 & 1,367 & 1,594 \\
\hline Total & 23,205 & 21,651 & 18,126 & 19,878 & 3,508 & 7,303 & 8,633 & 9,393 \\
\hline Average Transaction/customer & 2.113966 & 2.059058 & 1.804121 & 1.815508 & 3.239150508 & 6.74330563 & 7.97137581 & 8.68114603 \\
\hline
\end{tabular}

Source: Extract from the results of VAS users and non-VAS users in Sheet 1, and the author's research results 


\section{Conclusions}

In conclusion, the research sought to respond to the problem statement, whether the introduction, modification and communication of VAS had an effect on customers' transactional behaviour. This was done within the purview of the context and purpose of VAS in the South African banking sector, through conducting a case study at Bank $Z$ where the researcher was employed at the time. An experiment was carried out on Bank Z's products, namely Product $Y$ and Students account targeting the youth customer, using the Gauteng-based youth customers as a research sample. Out of the sample, an experiment group and a control group were selected wherein the control group received a single level of treatment and the experimental group received three more treatment levels. The data was compared to the period at the beginning and end of the intervention. The results confirmed the literature review findings on VAS, that amongst other things, the introduction of VAS alone did not lead to an increase or repeated customers' transactional behaviour, but customer engagement and awareness (through repeated communication and modification of the VAS) was what led to this increase (Bruneau et al., 2018:145). This in turn, resulted in increased usage of the account (Chauduri et al., 2019:640).

Furthermore, the research results were expected to reveal insights on VAS usage and trends which could be used to set targets and measure success, as well as enhancing personalisation and targeted marketing. Youth products were previously launched and introduced by Bank $\mathrm{Z}$ into the banking market without VAS, which saw the product sales remaining low, with more than half of the bank accounts remaining inactive. In response, the study highlighted how Bank $\mathrm{Z}$ responded to these observations by bundling VAS to the youth accounts and relaunching them, with an expectation that this would increase usage of the accounts by $50 \%$. The youth customers did not use the VAS or the accounts, and it is against this backdrop that the research was conducted, to determine whether the introduction, modification and communication of VAS had an effect on transactional behaviour.

Factors that contribute to the use of VAS by young customers, were driving their desired transactional behaviour. Such factors as customer engagement, customer experience, customers' social environment, consumer behaviour and value creation were emphasised as key to promoting the usage of VAS by the youth customer. The inclination to the use of mobile and Internet banking channels by the youth customers, also highlighted the need for placing priority on advertising, communication, relevance and value as considerations for success in encouraging VAS usage, as well as the bank's ability to understand the customer and continue providing solutions for them.

Section three of the research comprised of the research methodology wherein the procedure that was followed in collecting data and processing it, including the description of the methodology, the population sampled, the sample size and analysis of the collected data, were explained. The concerns regarding experimental error and validity were expressed. With the research question at the centre of the research procedure, method and approach, a quantitative positivist research approach was used to collect data in order to reach findings that would answer the research question.

The findings of the study showed a direct correlation between the introduction, modification and communication of VAS on the youth customers' transactional behaviour. The findings also showed that merely bundling VAS with the product, did not lead to the usage of the product. However, modifying the VAS, frequently communicating it to the youth customer (including how it is communicated by means of personalised messaging and modifying communication to the customers' transactional history) and creating rules (such as putting an expiry date for redemption of rewards), were what increased VAS usage.

\section{Managerial Implications}

To remain relevant or gain a competitive advantage, banks have to ensure that their products and services are not only attractive or appealing to the youth customer but are in fact also used by the customer. The banks may have achieved brand success by attracting the customer, however, the success of this customer segment lies in the frequent utilisation of its products and services. Therefore, in order to promote VAS and bank account or product usage, the bank must continue to meet the customers' needs. 


\section{Limitations and recommendations for future research}

Although the research used actual transactional data, strengthening the freedom from bias, it paid little attention to the motivations behind the selection of bank and bank products. Future research could explore the youth's perceptions of banking services, and factors that drive the selection and usage of a particular bank.

\section{References}

Al-Rabayah, W., Khasawneh, R., Abu-Shamaa, R. \& Alsmadi, I. (2017). Strategic uses of social media for improved customer retention, Hershey: IGI Global: Business Science Reference.

Bazargan, A., Zolfaghari, S. \& Karray, S. (2017). Modeling reward expiry for a loyalty program in a competitive market. International Journal of Production Economics, 193: 352-364.

Braciníková, V. \& Matušínská, K. (2016). Marketing communication of brand in the financial service brand communication. Marketing Identity, (2): 39-53.

Bruneau, V., Swaen, V. \& Zidda, P. (2018). Are loyalty program members really engaged? Measuring customer engagement with loyalty programs. Journal of Business Research, 91: 144-158.

Buszko, M., Krupa, D. \& Chojnacka, M. (2019). Young people and banking products and services in Poland: The results of empircal studies. Ekonomia i Prawo, 18(2): 147-164.

Chan, K., Tsang, L. \& Chen, J. (2017). Marketing bank service to youth in China. Young Consumers, 18(3): 278-289.

Chaudhuri, M., Voorhees, C.M. \& Beck, J.M. (2019). The effects of loyalty program introduction and design on shortand long-term sales and gross profits. Journal of the Academy of Marketing Science, 47(4): 640-658.

Chua, W.F. (2019). Radical developments in accounting thought? Reflections on positivism, the impact on rankings and research diversity. Behavioral Research in Accounting, 31(1): 3-20. doi: 10.2308/bria-52377.

De Jager, A. (2015). Why invest in the youth? Internal Bank Z report: Unpublished.

Dorotic, M., Verhoef, P.C., Fok, D. \& Bijmolt, T.H. (2014). Reward redemption effects in a loyalty program when customers choose how much and when to redeem. International Journal of Research in Marketing, 31(4): 339-355.

Hefner, D., Knop, K., Schmitt, S. \& Vorderer, P. (2019). Rules? Role model? Relationship? The impact of parents on their children's roblematic mobile phone involvement. Media Psychology, 22(1): 82-108.

Hoffman, B. (2019). The role of advertising in shaping children's preferences of consumption. Trakia Journal of Sciences, 17(2): 115-124.

Kalbach, J.S. (2016). Mapping experiences: A complete guide to creating value through journeys, blueprints and diagrams. s.l.:O'Reilly Media.

Kumar, S. \& Suresh, G. (2017). Effetiveness of value added services in public sector banks - a factor analysis. International Journal of Research in Commerce \& Management, 8(10): 19-24.

Kumar, V. \& Reinartz, W. (2016). Creating Enduring Customer Value. Journal of Marketing, 80(6): 36-68.

Löbler, H. \& Wloka, M. (2019). Customers' everyday understanding of 'value' from a second-or cybernetic perspective. Journal of Marketing Management, 35(11/12): 992-1014.

Mahalakshmi, V. \& Saravanaraj, M.G. (2013). Customers' perception about value added services rendered by banks. African Journal of Business Management, 7(29): 2845-2851.

Nastasoiu, A. \& Vandenbosch, M. (2019). Competing with loyalty: How to design successful customer loyalty reward programs. Business Horizons, 62(2): 207-214.

Nevskaya, Y. \& Albuquerque, P. (2019). How Should Firms Manage Excessive Product Use? A Continuous-Time Demand Model to Test Reward Schedules, Notifications, and Time Limits. Journal of Marketing Research (JMR), 56(3): 379-400.

Roberts-Lombard, M. \& Paramasur, S.B. (2015). Consumer Behaviour. Claremont: Juta and Company.

Salem, M.Z., Baidoun, S. \& Walsh, G. (2019). Factors affecting Palestinian customers' use of online banking services. International Journal of Bank Marketing, 37(2): 426-451.

Watson, G., Beck, J., Henderson, C. \& Palmatier, R. (2015). Building, measuring, and profiting from customer loyalty. Journal of the Academy of Marketing Science, 43(6): 790-825.

Wijland, R., Hansen, P. \& Gardezi, F. (2016). Mobile nudging: Youth engagement with banking apps. Journal of Financial Services Marketing, 21(1): 51-63.

Yin, R.K. (2018). Case study research and applications: design and methods. $6^{\text {th }}$ ed. Sage Publications, Los Angeles.

Zhang, A. (2017). Data analytics: Practical guide to leveraging the power of Algorithms, data science, data mining, statistics, big data, and predictive analysis to improve business, work, and life. CreateSpace Independent Publishing Platform. 